\title{
Identification and Evaluation of Human Errors in the Medication Process Using the Extended CREAM Technique
}

\author{
Iraj Mohammadfam, ${ }^{1}$ Saeed Bashirian, ${ }^{2}$ and Zohreh Bakhshi ${ }^{1, *}$ \\ ${ }^{1}$ Department of Occupational Health Engineering, School of Health, Hamadan University of Medical Sciences, Hamadan, IR Iran \\ ${ }^{2}$ Department of Health Education, School of Health, Hamadan University of Medical Sciences, Hamadan, IR Iran \\ "Corresponding author: Zohreh Bakhshi, Department of Occupational Health Engineering, School of Health, Hamadan University of Medical Sciences, Hamadan, IR Iran. Tel: \\ +98-9183122076, E-mail: z.bakhshi1390@yahoo.com
}

Received 2017 February 13; Revised 2017 April 17; Accepted 2017 April 30.

\begin{abstract}
Background: Medication process is a powerful instrument for curing patients. Obeying the commands of this process has an important role in the treatment and provision of care to patients. Medication error, as a complicated process, can occur in any stage of this process, and to avoid it, appropriate decision-making, cognition, and performance of the hospital staff are needed.

Objectives: The present study aimed at identifying and evaluating the nature and reasons of human errors in the medication process in a hospital using the extended CREAM method.

Methods: This was a qualitative and cross-sectional study conducted in a hospital in Hamadan. In this study, first, the medication process was selected as a critical issue based on the opinions of experts, specialists, and experienced individuals in the nursing and medical departments. Then, the process was analyzed into relative steps and substeps using the method of HTA and was evaluated using extended CREAM technique considering the probability of human errors.

Results: Based on the findings achieved through the basic CREAM method, the highest CFPt was in the step of medicine administration to patients (0.056). Moreover, the results revealed that the highest CFPt was in the substeps of calculating the dose of medicine and determining the method of prescription and identifying the patient (0.0796 and 0.0785, respectively). Also, the least CFPt was related to transcribing the prescribed medicine from file to worksheet of medicine (0.0106).

Conclusions: Considering the critical consequences of human errors in the medication process, holding pharmacological retraining classes, using the principles of executing pharmaceutical orders, increasing medical personnel, reducing working overtime, organizing work shifts, and using error reporting systems are of paramount importance.
\end{abstract}

Keywords: Medication Process, Medication Error, Extended CREAM, Patient Safety

\section{Background}

In the modern world, due to growth in medical and hygiene services, complicated equipment are used in performing related activities, and as a result, failures caused by such equipment have become an issue of discussion in the criterion of safety of patients (1). Protecting patient safety is one of the basic issues in the systems of providing health services (2), and this is considered as a main concern in the mentioned systems. Medication errors are considered as the commonest medical errors that are used nowadays as an index for determining the extent of patients' safety in hospitals because of their frequency of occurrence and probable dangers to patients (3). Medication is a powerful instrument for curing patients and executing its orders has a salient role in the process of curing patients and providing care for them (4). As medication errors and correct decision, cognition, and performance of the personnel working in hospital sections are complicated processes, errors can occur in each of the medication processes (5). Occurrence of medication errors can cause serious problems in public health and is considered as a threat to patients' safety (6). These errors are put in one of the 5 categories of medical errors made by the institute of medicine (IOM) (7). Medication errors have unpleasant consequences, such as increase in patient deaths, hospitalization periods, and medical expenses $(8,9)$. Occurrence of these errors results in distrust and dissatisfaction of patients from systems responsible for providing medical services (10). Based on the reports of IOM, about 1000 people die in the USA annually due to medication errors, and the financial expenses regarding these errors is about \$3.5 billion per year (11). Studies in European countries have revealed that $19 \%$ to $28 \%$ of hospitalized patients are victims of medication errors (12). These errors have adverse effects on patients, on medical personnel, and on health services and organizations, and finally they result in decreased quality of care. Therefore, identifying the reasons of their occurrence and taking the necessary measures to reduce them can be considered as priorities of health sys- 
tems research.

Therefore, to increase the safety of patients, it is important to take measures with the goal of controlling preventable errors and unpleasant events (13). Precise identification of medical errors and unpleasant events is a key to improvement and advancement in successfully preventing errors and decreasing the costs of health care (14). Thus, to take effective measures, we should have a good understanding of errors.

There are various methods for identifying and evaluating errors in all professions. The cognitive reliability error analysis method (CREAM) was provided by Hollnagel in 1998. This method is a frequently used second generation HRA technique in the safety science literature, with detailed theoretical literature, and concentrates on the cognitive grounds of human behaviors $(15,16)$.

Because of the capabilities of the extended CREAM method in identification and quantitative assessment of human errors in steps and substeps of related processes and also determining the mode of existing controls and role of factors affecting the performance rate of human errors, this method was used in this study. It is evident that in several studies, CREAM method, which is used to identify and assess human errors, has been used in various fields, such as health care system. For example, the studies of Mohammadfam et al. and others can be noted (3, 4,16-23).

\section{Objectives}

The present study aimed at identifying and assessing human errors in medication process using the extended CREAM method. This was a cross-sectional study conducted in a hospital in Hamadan. The findings of this study can help identify the reasons for the occurrence of human errors and help reduce them and their consequences and thus reduce the medical expenses and hospitalization time, and at the same time, increase satisfaction and patients' trust in the medical environment and personnel.

\section{Methods}

This was a qualitative and cross-sectional study conducted in a hospital in Hamadan. In this study, first, the medication process was selected as a critical issue based on the opinions of experts, specialists, and experienced people in the nursing and medical departments. Afterwards, the process was evaluated using extended CREAM technique to determine the probability of human errors.

Based on principles of the method selected, the stages of this study were as follow:
3.1. Analyzing the Desired Process Using Hierarchical Task Analysis (HTA) Method

In this study, for analysis, the process was categorized into relative steps and substeps by HTA method (24).

\subsection{Evaluating Common Performance Conditions (CPCs)}

In this stage, through using the field study, interviewing the medical personnel of the hospital, and observing the documents, the general features of each process and conditions of work that affected the performances of users were analyzed using the CPCs table from the extended CREAM method. To determin CPCs through interviews, using the following questions, 23 medical staff, who were involved in medication process, were asked to rate the effectiveness of each CPC on the steps of the process (Table 1).The conditions that resulted in improved or reduced performance or those that had no effect were identified, and the total number for each step of the study was counted. These conditions included 9 factors, which were individual, technical, or instrumental.

\subsection{Determining the Coefficient of Control Mode $(\beta)$ and Con- trol Modes}

At this stage, the total number of all activities that resulted in the reduction of performance ( $\sum \mathrm{R}$ ) was subtracted from the ones resulting in improving the performance ( $\sum \mathrm{I}$ ) (Equation 1). The number achieved was used to determine the probable controls of performers for each step.

$\beta=\sum R-\sum I$

\subsection{Determining the Cognitive Failure Probability Total (CFPt)}

In this stage, with $\beta$ and using the equation of CFPt (Equation 2), the cognitive failure probability total was calculated for each step.

$C F P t=0.0056 \times 10^{0.25 \beta}$

3.5. Obtaining the Number of Performance Influence Index (PII) and Context Influence Index (CII) for Each Activity

Using the results achieved through basic CREAM, the number of performance influence index (PII) was determined for each CPC relative to each step of the medication process using the database of the relative table. As the number of CPCs is 9, 9 PIIs should be determined for each step of the process. Then, using Equation 3, the number of context influence index (CII) was determined for each step of the medication process.

$C I I=\sum_{i=1}^{9} P I I$ 
Table 1. CPCs and Performance Reliability

\begin{tabular}{|c|c|c|}
\hline CPC/Description & CPC Level & Effects \\
\hline \multirow{4}{*}{$\begin{array}{l}\text { Adequacy of organization: The quality of the support and resources provided by the management for the } \\
\text { job being performed. }\end{array}$} & Very efficient & Improved \\
\hline & Efficient & Not significant \\
\hline & Inefficient & Reduced \\
\hline & Deficient & Reduced \\
\hline \multirow{3}{*}{$\begin{array}{l}\text { Working conditions: The conditions under which the job takes place, such as insufficient lighting, heat, } \\
\text { noise, interruptions from the task etc. }\end{array}$} & Advantageous & Improved \\
\hline & Compatible & Not significant \\
\hline & Incompatible & Reduced \\
\hline \multirow{4}{*}{$\begin{array}{l}\text { Adequacy of MMI and operational support: The quality of the MMI and/or specific operational support } \\
\text { provided for operators. }\end{array}$} & Supportive & Improved \\
\hline & Adequate & Not significant \\
\hline & Tolerable & Not significant \\
\hline & Inappropriate & Reduced \\
\hline \multirow{3}{*}{ Availability of procedures/plans: The availability of prepared procedure for the job to be carried out. } & Appropriate & Improved \\
\hline & Acceptable & Not significant \\
\hline & Inappropriate & Reduced \\
\hline \multirow{3}{*}{ Number of simultaneous goals: The number of activity operators must attend to. } & Fewer than capacity & Not significant \\
\hline & Matching current capacity & Not significant \\
\hline & More than capacity & Reduced \\
\hline \multirow{3}{*}{ Available Time: The time available to complete the task. } & Adequate & Improved \\
\hline & Temporarily inadequate & Not significant \\
\hline & Continuously inadequate & Reduced \\
\hline \multirow{2}{*}{ Time of day (circadian rhythm): The time at which the work is carried out. } & Day-time (adjusted) & Not significant \\
\hline & Night-time (unadjusted) & Reduced \\
\hline \multirow{3}{*}{$\begin{array}{l}\text { Adequacy of training and preparation: The level of readiness for the work as provided through training } \\
\text { and prior instruction. }\end{array}$} & Adequate, high experience & Improved \\
\hline & Adequate, limited experience & Not significant \\
\hline & Inadequate & Reduced \\
\hline \multirow{4}{*}{ Crew collaboration quality: The quality of collaboration between employment. } & Very efficient & Improved \\
\hline & Efficient & Not significant \\
\hline & Inefficient & Not significant \\
\hline & Deficient & Reduced \\
\hline
\end{tabular}

\subsection{Presenting the Cognitive Demands}

In this stage, the cognitive demands were determined according to each substep of the medication process using the table of cognitive activities to establish cognitive demands and determine cognitive features and the probability of cognitive failures needed for each substep.

\subsection{Recognition of Probable Cognitive Errors}

After determining each cognitive demand relative to each substep of the medication process, the probable cognitive errors for each substep were determined in the 4 groups of observation, interpretation, planning, and execution. Then, the basic values (CFP0) for each of them were recognized.

3.8. Evaluating the Cognitive Failure Probability (CFPi) as Quantitative

In this stage, considering the numbers found from the previous stages and the ones found using Equation 4 for each step of the process, the amount of the final CFP for each substep was calculated $(17,25)$.

Equation 4. 
$C F P=C F P_{0} \times 10^{0.25 C I I}$

\section{Results}

Using the HTA method, the medication process was divided into 6 steps of physician's prescription, rechecking and transcribing by nurses, finding and preparing medicine, recognizing and preparing patients, medicine administration to patient, and documentation. CFPts for each of the steps are summarized in Table 2 with their control modes.

Using the extended CREAM method and determining the main substep of each step, the CFPi of each of them was determined (Table 3). In this process, the largest amount of CFPi was in the substeps calculation of doses of medicine and determining the method of prescription by physicians and recognizing patients (0.0796 and 0.0785, respectively), and the least amount was in the substep transcription of the prescribed medicine from file to worksheet of medicine (0.0106).

Also, results of the extended CREAM method revealed that $55 \%$ of the total identified cognitive failures in the medication process were related to execution error, $25 \%$ to observation error, and $10 \%$ to interpretation error.

Observing the profile of cognitive demands, these activities were identified for medication process as follow: activities executed (25\%), identification (20\%), record (20\%), evaluation (15\%), diagnosis (10\%), monitoring (5\%), and communication (5\%).

\section{Discussion}

In recent years, there have been numerous studies regarding the criticality of the medication process. In this study, based on the findings achieved by the basic CREAM method, the highest CFPt is related to the step of medicine administration to the patient (0.056). In the study of Ruiz et al., after analyzing the medication errors in a neonatal ward of a hospital, it was found that the highest reported rate of medication errors was related to error in medicine administration to patient (68.1\%), followed by error in prescription of medicine (39.5\%) (26). Also, in another study, it was found that in the process of medication, most errors occurred at the time of prescription and medicine administration to the patient (27). In another study done by Port et al., with the goal of observation of prescription of medicine for patients, the results revealed that $36 \%$ of errors occurred at the time of giving medicine to patients, $19 \%$ in the method of consumption of medicine, $15 \%$ in the amount of medicine, and $10 \%$ in the prescription of medicine without doctors' prior order(28). Also, in a study done by Choi et al., on the medical expenses and their increase because of medication errors for hospitalized patients, most errors were observed in the stage of drug administration to the patient by nurses (189 errors) (29). In the study of Mohammadnejad et al. on the analysis of the extent and type of medication errors in nursing students, it was revealed that the commonest type of medication errors was error in dose and type of medicine and the commonest reasons for medication errors was error in writing the name and dose of medicine in pharmaceutical worksheets, moreover, most errors occurred in IV therapies (51.35\%) (30). In a similar study in a psychiatric hospital, the most frequent error was incorrect dose omission (52/139, 37\%). Other frequent errors included incorrect dose (25/139,18\%), incorrect form (16/139,12\%), and incorrect time $(12 / 139,9 \%)(31)$. The results of all these studies agreed with those of our study.

According to the basic CREAM method, the factors related to decrease in the reliability of performance (CPCs) were number of simultaneous goals, available time for performing a task, time of day, and adequacy of training and experience. They result in errors in passing through steps of the medication process and the style of opportunistic control. Mohammadfam et al. in a study, whose goal was to recognize and evaluate the nature and reasons of human errors of CCU nurses in a hospital, used CREAM technique and stated that the 2 factors of performing 2 or more tasks at the same time and the availability of time to work were the main reasons for occurrence of errors in performances of nurses (4). Also, in a study done by Jolaee et al. about the analysis of occurrence and report of medication errors of nurses and their relations with work conditions in a hospital, they found a significant relationship between medication errors of nurses and their work conditions. In proper work conditions, there was less probability of medication errors compared to improper ones (32). The results of the study done by Beidokhty et al. revealed that illegible orders of the physician, lack of personnel, high workload, and overtime work of medical personnel are some of the effective factors in medication errors (33). Also, Reason, in his study, found that work conditions, such as lack of time, lack of personnel, improper facilities, and lack of experience, result in an increase in unsafe clinical activities and occurrence of clinical errors (34). Seki et al. acknowledged that working conditions also lead to clinical errors, but little attention has been paid to this matter (35). The results of this study were in agreement with those of the current study.

In the basic CREAM method, the goal was to increase the reliability of performance and decrease the CFPt, for which the type control mode must move from opportunistic to strategic (16). Therefore, based on the findings of 
Table 2. Results of the Basic CREAM Method in the Medication Process

\begin{tabular}{llr}
\hline Step & CFPt & Control Mode \\
\hline Physician's prescribing & 0.0177 & Opportunistic control \\
\hline Checking again and transcribing & 0.0177 & Opportunistic control \\
\hline Finding and preparing medicine & 0.0315 & Opportunistic control \\
\hline Recognizing and preparing patient & 0.0315 & Opportunistic control \\
\hline Medicine administration to patient & 0.0560 & Opportunistic control \\
\hline Documenting & 0.0099 & Tactical control \\
\hline
\end{tabular}

Table 3. Results of the Extended CREAM Technique in the Medication Process

\begin{tabular}{|c|c|c|c|c|c|}
\hline Step & Substep & Cognitive Activity & Cognitive Function & Generic Failure Type & CFP Adjusted \\
\hline \multirow{3}{*}{ Med1.Physician's prescription } & $\begin{array}{l}\text { Med 1.1- getting accurate } \\
\text { information about patients } \\
\text { including age (children) and } \\
\text { weight by physician }\end{array}$ & Identification & Observation & Wrong identification & 0.0278 \\
\hline & $\begin{array}{l}\text { Med 1.2- calculating the dose of } \\
\text { medicine and determining the } \\
\text { method of prescription }\end{array}$ & Diagnosis & Interpretation & Faulty diagnosis & 0.0796 \\
\hline & $\begin{array}{l}\text { Med 1.3- recording the stages of } \\
\text { calculation of medical doses and } \\
\text { the method of prescription in the } \\
\text { papers of physicians' orders }\end{array}$ & Record & Execution & Action of wrong type & 0.0119 \\
\hline \multirow{2}{*}{ Med6. Documenting } & $\begin{array}{l}\text { Med 6.1- recording equipment and } \\
\text { consumptive instruments of } \\
\text { patient in HIS system }\end{array}$ & Record & Execution & Action of wrong type & 0.0119 \\
\hline & $\begin{array}{l}\text { Med 6.2- recording the done } \\
\text { efforts and observations of nurse } \\
\text { in the papers of nurse report }\end{array}$ & Record & Execution & Action of wrong type & 0.0119 \\
\hline
\end{tabular}

this study, the CPCs could improve, the reliability of performance of medical personnel could increase, and the CPCs could decrease through specialized training, retraining scientific and practical skills, increasing personnel, decreasing overtime work, and organizing work shifts.

According to findings achieved via the extended CREAM method for the medication process in the current study, it was found that the highest probability of cognitive failure was related to the substep of "calculating pharmaceutical dose and determining the method of prescription" in the step of physician's prescription (0.0796). In a study done by Jalalifar et al. it was found that errors in determining the dosage of medicine or not writing the dose of medicine in the doctors' orders were the most common errors in prescription step. On the other hand, insufficiency of pharmaceutical knowledge was one of the main reasons for the occurrence of errors in the prescription and administering drug steps (36). In the study of Taheri et al. on analyzing the type and amount of medication errors in the neonatal ICU of 5 training hospitals, it was revealed that medication errors in injectable drugs were recognized in this order: error in the time of drug administration (51\% to $60 \%$ ), error in pharmaceutical calculations (51\% to $60 \%$ ), and wrong dosage of a drug ( $41 \%$ to $50 \%$ ) (37). In the study of Micro et al., which analyzed the process of prescription of medicine in internal medicine department, the commonest reasons of medication errors were illegibility of pharmaceutical commands in the files of patients (13.3\%), error in preparing the dose of the medicine (30\%), and error in prescribing the type of medicine (28.3\%) (38). Also, in the study of Heydari et al., findings revealed that in ranking the reasons for medication errors, nurses considered the illegibility of the order of physicians as the most salient and damage to pharmaceutical labels as the least important (39). Also, in the study of Enguidanos and Brumley, the most important causes of medication errors were legibility, use of medical abbreviations, and incomplete and missing entries (40).

In the second rank, the highest probability of cognitive failure was 0.0785 in the substep of recognition of patients. The study of ebrahimpour et al. on the analysis of patient safety and nurses' errors in the execution of phar- 
maceutical orders revealed that the commonest medication errors were giving medicine to wrong patients and error in recognizing patients (36\%) (41). According to the extended CREAM technique, the most identified failures were errors in execution, observation, and interpretation; and the most important cognitive activities were activities of execution, identification, recording, evaluation, and diagnosis.

Although the extended CREAM technique has provided quantification of human error in the process, relying on the role of CPCs on observations, interviews, and document review are the weaknesses of this technique.

The major limitation of this study was the difficult access to the documentation related to human errors in hospitals.

\subsection{Conclusions}

Error is a part of normal human behavior and is also unavoidable in health care. Considering the critical consequences of human errors in the medication process, to decrease medication errors and increase patient safety the following efforts are highly recommended: updating knowledge of health experts about the errors of the medication process through holding retraining classes of pharmacology and principles of execution of pharmaceutical orders; increasing medical personnel; decreasing overtime working; organizing work shifts; using error reporting systems; evaluating errors periodically to inform the personnel about possible errors and their frequencies of occurrence; encouraging the medical personnel to report errors in medication process; gaining experience to prevent the recurrence of errors; and promoting patient safety culture.

\section{Acknowledgments}

This paper is a part of an MSc thesis of the first author in Hamadan University of Medical Sciences, Hamadan, Iran. The authors would like to acknowledge Hamadan University of Medical Sciences for funding and supporting this project (grant No.9412046697).

\section{References}

1. Robinson AR, Hohmann KB, Rifkin JI, Topp D, Gilroy CM, Pickard JA, et al. Physician and public opinions on quality of health care and the problem of medical errors. Arch Intern Med. 2002;162(19):2186-90. [PubMed: 12390060].

2. Stetina P, Groves M, Pafford L. Managing medication errors-a qualitative study. Medsurg Nurs. 2005;14(3):174-8. [PubMed:16035634].

3. Mohammadfam I, Movafagh M, Bashirian S. Comparison of Standardized Plant Analysis Risk Human Reliability Analysis (SPAR-H) and Cognitive Reliability Error Analysis Methods (CREAM) in Quantifying Human Error in Nursing Practice. Iran J Public Health. 2016;45(3):401-2. [PubMed: 27141509].
4. Mohammadfam I, Movafagh M, Soltanian A, Salavati M, Bashirian S. Identification and evaluation of human errors among the nurses of coronary care unit using CREAM techniques. J Ergonom. 2014;2(1):2735.

5. Cassiani SH. [Patient safety and the paradox in medication use]. Rev Bras Enferm. 2005;58(1):95-9. [PubMed: 16268293].

6. Grissinger MC, Kelly K. Reducing the risk of medication errors in women. $J$ Womens Health (Larchmt). 2005;14(1):61-7. doi: 10.1089/jwh.2005.14.61. [PubMed: 15692279].

7. Mohammadfam I, Saeidi C. Evaluating human errors in cataract surgery using the SHERPA technique. J Ergon. 2015;2(4):41-7.

8. Mihailidis A, Krones L, Boger J. Assistive computing devices. Computer Informat Nurs. 2006;24(6):328-36. doi: 10.1097/00024665-20061100000007.

9. Webster CS, Anderson DJ. A practical guide to the implementation of an effective incident reporting scheme to reduce medication error on the hospital ward. Int J Nurs Pract. 2002;8(4):176-83. doi: 10.1046/j.1440-172X.2002.00368.x.

10. Donaldson MS, Corrigan JM, Kohn LT. To err is human: building a safer health system. National Academies Press; 2000.

11. Taylor P. Preventing medication errors. Jama. 2007;297(15):1717. doi: 10.1001/jama.297.15.1717.

12. Johnstone MJ, Kanitsaki O. The ethics and practical importance of defining, distinguishing and disclosing nursing errors: a discussion paper. Int J Nurs Stud. 2006;43(3):367-76. doi: 10.1016/j.ijnurstu.2005.04.010. [PubMed: 15979075].

13. Johnstone MJ. Patient safety ethics and human error management in ED contexts. Australasian Emerg Nurs J. 2007;10(1):13-20. doi: 10.1016/j.aenj.2006.09.002.

14. Kalra J, Kalra N, Baniak N. Medical error, disclosure and patient safety: a global view of quality care. Clin Biochem. 2013;46(13-14):1161-9. doi: 10.1016/j.clinbiochem.2013.03.025. [PubMed: 23578740].

15. Andrews LB, Stocking C, Krizek T, Gottlieb L, Krizek C, Vargish T, et al. An alternative strategy for studying adverse events in medical care. Lancet. 1997;349(9048):309-13. doi: 10.1016/S0140-6736(96)08268-2. [PubMed: 9024373].

16. Mohammadfam I, Amid M, Aliabadi MM, Hajiakbari M, Soltanian A The study of human errors in de-mining operations using the CREAM technique. J Military Med. 2016;17(4):241-7.

17. Akyuz E, Celik M. Application of CREAM human reliability model to cargo loading process of LPG tankers. J Loss Prev Process Ind. 2015;34:39-48. doi:10.1016/j.jlp.2015.01.019.

18. Liao PC, Luo X, Wang T, Su Y. The mechanism of how design failures cause unsafe behavior: The cognitive reliability and error analysis method (CREAM). Procedia Engin. 2016;145:715-22.

19. Mazlomi A, Hamzeiyan Ziarane M, Dadkhah A, Jahangiri M, Maghsodipour M, Mohadesy P. Assessment of human errors in an industrial petrochemical control room using the CREAM method with a cognitive ergonomics approach. J School Public Health Inst Public Health Res. 2011;8(4):15-30.

20. Zhou Q, Wong YD, Xu H, Thai VV, Loh HS, Yuen KF. An enhanced CREAM with stakeholder-graded protocols for tanker shipping safety application. Safety Sci. 2017;95:140-7. doi:10.1016/j.ssci.2017.02.014.

21. Desmorat G, Guarnieri F, Besnard D, Desideri P, Loth F. Pouring CREAM into natural gas: The introduction of Common Performance Conditions into the safety management of gas networks. Safety Sci. 2013;54:1-7. doi: 10.1016/j.ssci.2012.10.008.

22. Lee SM, Ha JS, Seong PH. CREAM-based communication error analysis method (CEAM) for nuclear power plant operators' communication. J Loss Prev Process Ind. 2011;24(1):90-7. doi:10.1016/j.jlp.2010.10.002.

23. Marseguerra M, Zio E, Librizzi M. Quantitative developments in the cognitive reliability and error analysis method (CREAM) for the assessment of human performance. Ann Nucl Energy. 2006;33(10):894910. doi: 10.1016/j.anucene.2006.05.003. 
24. Stanton NA. Hierarchical task analysis: developments, applications, and extensions. Appl Ergon. 2006;37(1):55-79. doi: 10.1016/j.apergo.2005.06.003. [PubMed: 16139236].

25. Li PC, Chen G, Dai L, Li Z. Fuzzy logic-based approach for identifying the risk importance of human error. Safety Sci. 2010;48(7):902-13. doi: 10.1016/j.ssci.2010.03.012.

26. Esqué Ruiz MT, Moretones Sunol MG, Rodríguez Miguelez JM, Sanchez Ortiz E, Izco Urroz M, de Lamo Camino M, et al. Medication errors in a neonatal unit: One of the main adverse events. Anales de Pediatria (English Edition). 2016;84(4):211-7. doi: 10.1016/j.anpede.2015.09.036.

27. Lassetter JH, Warnick ML. Medical errors, drug-related problems, and medication errors: a literature review on quality of care and cost issues.J Nurs Care Qual. 2003;18(3):175-81. [PubMed:12856901] quiz182-3.

28. Prot S, Fontan JE, Alberti C, Bourdon O, Farnoux C, Macher MA, et al. Drug administration errors and their determinants in pediatric in-patients. Int J Qual Health Care. 2005;17(5):381-9. doi: 10.1093/intqhc/mzi066. [PubMed: 16115809].

29. Choi I, Lee SM, Flynn L, Kim CM, Lee S, Kim NK, et al. Incidence and treatment costs attributable to medication errors in hospitalized patients. Res Social Adm Pharm. 2016;12(3):428-37. doi 10.1016/j.sapharm.2015.08.006. [PubMed: 26361821].

30. Mohammad Nejad I, Hojjati H, Sharifniya SH, Ehsani SR. Evaluation of medication error in nursing students in four educational hospitals in Tehran. Iranian J Med Ethics History Med. 2010;3:60-9.

31. Cottney A, Innes J. Medication-administration errors in an urban mental health hospital: a direct observation study. Int J Ment Health Nurs. 2015;24(1):65-74. doi:10.1111/inm.12096. [PubMed: 25394525].

32. Jolaee S, Hajibabaee F, Peyravi H, Haghani H. Nursing medication errors and its relationship with work condition in Iran University of Medical Sciences. Iranian J Med Ethic History Med. 2009;3(1):65-76.
33. Baloochi Beydokhti T, Mohammad Pour A, Shabab S, Nakhaee H. Related factors of medication errors and barriers of their reporting in the medical staff in hospitals of Gonabad University of Medical Sciences. QHMS. 2014;19(5):289-95.

34. Mohamadfam I, Nikomaram H, Yoosefi H, Pirhadi M. Assessment and management of human errors in emergency situations by HEPI method (case study: a Manufacturing industry). Jundishapur J Health Sci. 2013;4(4):47-58.

35. Seki Y, Yamazaki Y. Effects of working conditions on intravenous medication errors in a Japanese hospital. J Nurs Manag. 2006;14(2):128-39. doi: 10.1111/j.1365-2934.2006.00597.x. [PubMed:16487424].

36. Jalalifar F, MM S. Medication process analytics, errors recognition, and contributory factors in creation of the errors. Quarterly J Nurs Manag. 2015;4(4):67-81.

37. Taheri E, Nourian M, Rasouli M, Kavousi A. The study of type and amount of medication errors in neonatal intensive care units and neonatal units. Iran J Crit Care Nurs. 2013;6(1):21-8.

38. Mirco A, Campos L, Falcao F, Nunes JS, Aleixo A. Medication errors in an internal medicine department. Evaluation of a computerized prescription system. Pharm World Sci. 2005;27(4):351-2. doi: 10.1007/s11096-005-2452-z. [PubMed:16228636].

39. Heydari H, Kamran A, Pirzadeh A. Assessment of nurses'perceived barriers and behaviors to reporting medication errors in hospitals of Lorestan University of Medical Sciences, Iran. Health System Res. 2012;8(5):806-13.

40. Enguidanos SM, Brumley RD. Risk of medication errors at hospital discharge and barriers to problem resolution. Home Health Care Serv Q. 2005;24(1-2):123-35. doi: 10.1300/J027v24n01_09. [PubMed: 16236663].

41. Ebrahimpour F, Shahrokhi A, Ghodousi A. Patients' safety and nurses' medication administration errors. IJFM. 2014;20(1):401-8. 